\title{
f2f and cyberbullying among children in Northern Ireland: Data from the Kids Life and Times Surveys
}

\author{
Conor Mc Guckin ${ }^{1 *}$, Pauline K. Cummins ${ }^{2}$, and Christopher Alan Lewis ${ }^{2}$ \\ ${ }^{\prime}$ School of Education, Trinity College Dublin, Dublin 2, Ireland \\ ${ }^{2}$ Division of Psychology, Glyndŵr University, Wrexham, Wales \\ (Received March 20, 2010; Accepted June 8, 2010)
}

\begin{abstract}
Comparatively little is known about the nature, incidence and correlates of bully/victim problems in the Northern ireland school system. The present study examined the prevalence of self-reported experiences of bully/ victim problems (f2 $f$ and cyber), and the relationship between such experiences and levels of psychological wellb eing among representative samples of primary school pupils who participated in the 2008 and 2009 'Kids Life and Times Survey' (ArK, 2008, 2009). bully/victim problems among these children were pervasive. Personal experience of involvement in bully/victim problems was associated with impaired psychological well-b eing. Findings are interpreted within the context of previous data from Northern ireland and the wider international literature on bully/victim problems.
\end{abstract}

Keywords: bully, victim, cyberbullying, Northern ireland, health, well-b eing.

f2f y cyberbullying entre niños de Irlanda del Norte: Datos de las Encuestas sobre Vida y Uso del Tiempo de la Infancia

RESUMEN: Se sabe relativamente poco sobre la naturaleza, prevalencia y los correlatos de los problemas de bullying en el sistema educativo de irlanda del Norte. El presente estudio examina la prevalencia, a partir de autoinformes, de los problemas de bullying (cara a cara -f $2 \mathrm{f}-\mathrm{y}$ cyber) y las relaciones entre estas experiencias y el grado de bienestar psicológico en muestras representativas de alumnos de primaria que participaron en 2008 y 2009 en las Encuestas sobre vida y Uso del Tiempo de la infancia (ArK, 2008, 2009). Los problemas de bullying entre los alumnos fueron frecuentes en toda la muestra. Las experiencias personales de implicación en los problemas de bullying se asociaron a peores puntuaciones en bienestar psicológico. Los resultados se han interpretado en el contexto de los datos obtenidos en irlanda del Norte con anterioridad y en relación a la investigación internacional sobre los problemas de bullying.

Palabras clave: agresor, víctima, cyberbullying, irlanda del Norte, salud, bienestar. 
bully/victim problems among school pupils is an international problem (see Smith, Morita, junger- Tas, olweus, Catalano, \& Slee, 1999 for a review). We are at a stage where we have a robust cross- national knowledge of intervention and prevention programmes in the area (Smith, Pepler, \& rigby, 2004). Cou-

\section{Correspondence: Conor Mc Guckin, Anti-bullying Centre, School of Education, Trinity} College dublin, dublin 2, ireland. E-mail: conor.mcguckin@tcd.ie

pled with this increased knowledge regarding 'traditional' bully/victim problems (also referred to as 'face -to- face', or ' $\mathrm{f} 2 \mathrm{f}$ ' bullying), we are also at the stage where we are increasing our knowledge of new, more contemporary, forms of such problems, such as cyberbullying (e.g., Campbell, 2005; Patchin \& Hinduja, 2006; Smith, Mahdavi, Carvalho, \& Tippett, 2006; ybarra \& Mitchell, 2004, 2007; ybarra, Mitchell, Wolak, \& Finkelhor, 2006).

involvement in such problems is associated with a range of impaired life (e.g., criminality: Eron, Huesmann, dubow, romnanoff, \& yarnell, 1987; olweus, 1991), health (see Hawker \& boulton, 2000, for a review), and educational experiences (Nansel, overpeck, Haynie, ruan, \& Scheidt, 2003; Neary \& joseph, 1994; yang, Chung, \& Kim, 2003).

However, considering that Northern ireland is emerging from almost four decades of ethno political conflict (Cairns \& Darby, 1998; see http://cain.ulst.ac.uk and http://www.incore.ulst.ac.uk), whilst Mc Guckin and Lewis (2008) have provided information on the management of bully/victim problems in Northern ireland's schools (see Ananiadou \& Smith 2002 for a review of legal requirements in European countries), comparatively little is known about the nature, incidence and correlates of bully/victim problems among Northern ireland school pupils (Mc Guckin \& Lewis, 2003).

in Northern ireland, as elsewhere, much of the research exploring bully/victim problems has been largely sporadic in nature, resulting in a smorgasbord of findings that in combination provide a rich tapestry of findings from which is beginning to emerge a picture of the nature, prevalence and correlates of bully/ victim problems in Northern ireland. However, this picture is based on only a few studies, and further research is required to provide a better understanding of the problem. indeed, with no consensus among researchers, studies to date have differed in terms of the emphasis placed upon methodological issues such as the time- reference period for the events to have happened within (e.g., previous week, previous two months, previous year), and whether or not questionnaires were used that would allow for international comparisons (Callaghan \& joseph, 1995; Collins \& bell, 1996; Collins, Mc Aleavy, \& Adamson, 2002, 2004; Grant, 1996; Livesey, Mc Aleavy, donegan, duffy, o’Hagan, Adamson, \& White, 2007; Taylor, 1996).

of note has been the robust methodological approach taken by of Collins et al. (2002, 2004). Utilising olweus' (1989) 'goldstandard' bully/victim Questionnaire (bvQ) among a representative sample of 3,000 pupils from 120 schools (60 primary; 60 post -primary), $40.1 \%$ of primary students and $30.2 \%$ of post- primary students claimed to have been bullied during the period of the study 
(March 2000-j une 2000). indeed, 5\% of the primary pupils and 2\% of the postprimary pupils reported that they had suffered bullying for several years. regarding taking part in bullying others at school, this was reported by approximately a quarter (24.9\%) of the primary pupils and $29 \%$ of the postprimary pupils. Collins et al. $(2002,2004)$ also asserted that all of the evidence indicated that bullying was happening even in the best regulated schools, was not age or gender -specific, and was sometimes underplayed by the schools and teachers.

Utilising the same methodology, Livesay et al.'s (2007) follow up to the work of Collins et al. $(2002,2004)$ found similar prevalence rates. Among 993 primary and 1,319 post- primary pupils, it was found that $16.5 \%$ of primary and $7.6 \%$ of post -primary pupils reported being bullied 'sometimes or more often' and $5 \%$ of primary and $2.8 \%$ of post- primary pupils reported bullying others 'sometimes or more often.' in a move towards presenting a more coherent and systematic report of the prevalence of bully/victim problems, and the association between involvement and health and well-b eing among the Province's school pupils, Mc Guckin and Lewis (2006), Mc Guckin, Lewis, and Cummins (in press [a]) and Mc Guckin, Cummins, and Lewis (in press [b]) have reported upon data collected as part of the representative 'youth Life and Times Survey' (yLTS). The yLTS is conducted annually by ArK, the Northern ireland Social and Political Archive (a joint project by the two Northern ireland universities; University of Ulster and the Queen's University of belfast see http://www.ark.ac.uk/nilt). yLTS records the attitudes and experiences of 16 year olds in Northern ireland. Whilst the yLTS is not focused solely upon school related issues (e.g., environment, politics), its representative nature presents highly meaningful data on issues that affect Northern Irish adolescents. Through consultation with researchers in the field, the content and focus of the yLTS regarding bully/victim problems has developed significantly. From the first iteration in 1998 when only one question regarding involvement in bully/victim problems was included, more recent iterations have seen the inclusion of bully/victim items that can be fully interpreted to the international literature, with the inclusion also of the General Health Questionnaire (12 item: Goldberg \& Williams, 1988) and questions relating to stress so as to assess psychological health and well- being.

Mc Guckin and Lewis (2006), among the representative sample of 39712 to 17 year olds who completed the 1998 iteration of the yLTS, reported a victimization rate of $76.8 \%$ in response to the question 'Would you say that students at your school get bullied by other students?'.

Mc Guckin et al. (in press [a]), among the representative sample of 82416 year olds who completed the 2004 iteration of the yLTS, reported a victimization rate of 13\% $(n=107)$ (frequency = 'sometimes or more often') in response to the statement ' $\mathrm{i}$ was bullied at school'. Whilst nearly two- thirds of respondents $(65.7 \%, n=541)$ reported being stressed, approximately one- quarter $(23.8 \%, n$ = 189) scored high enough on the GHQ -12 (Goldberg \& Williams, 1988) to be classified as a 'case' (utilising a cut -off score of four: Mc Whirter, 2004). indeed, direct involvement in bully/victim problems was found to be associated with 
impaired psychological health in terms of increased stress $(r=-0.21, p<0.01$, 1 - tailed) and lower general psychological well- being $(r=0.21, p<0.01,1$ tailed).

Mc Guckin et al. (in press [b]) among a representative sample of 81916 year olds who completed the 2005 iteration of the yLTS, reported a victimization rate of $30.4 \%(n=244)$. Whilst nearly two- thirds $(64.7 \%, n=522)$ of respondents reported being stressed, almost one quarter $(21.4 \%, n=172)$ were scoring high enough on the GHQ -12 (Goldberg \& Williams, 1988) so as to require psychiatric referral (also utilising a cut-o ff score of four: Mc Whirter, 2004). direct experience of involvement in bully/victim problems was significantly associated with self- reported stress $(\mathrm{r}=0.17, \mathrm{p}<0.01,1$ - tailed $)$ and impaired psychological wellbeing $(r=-0.16, \mathrm{p}<0.01,1$ - tailed $)$.

in combination with previous research from the Province, these data provide a valuable insight into the nature, incidence, and correlates of bully/victim problems among children and young people in Northern ireland. However, in recognition of the fact that the opinions of children are often ignored when decisions are made about many of the issues involving them, ArK's new 'Kids' Life and Times Survey' (KLT: see http://www.ark.ac.uk/klt) gives children in Northern Ireland a voice and an opportunity to help influence policies that affect them. The aim of the present study was to supplement the research findings previously reported in Northern ireland by examining the experiences of 11 years old Northern Irish primary school pupils sampled as part of the first two KLT surveys $(2008,2009)$.

\section{METHod}

\section{Respondents}

The target population of the surveys were all 11 year-o ld children in Northern Ireland completing the final year of primary school education (including hospital and special schools, children who were being taught at home, and children who were not in school).

In 2008, of the 918 schools identified for participation $(\mathrm{N}=24,726$ pupils), almost one- quarter $(23.6 \%, n=217)$ participated in the survey. A total of 3,440 pupils participated, representing approximately $14 \%$ of pupils overall.

In 2009, of the 906 schools identified for participation ( $\mathrm{N}=24,030$ pupils), almost one- third $(30 \%, n=268)$ participated in the survey. A total of 3,699 pupils participated, representing approximately $15 \%$ of pupils overall.

Due to the anonymity of the surveys, exact figures regarding the number of children being taught at home or within special units were not available for both iterations of the survey. Thus, response rates are approximations.

\section{Measures}

The 2008 iteration of the Kids Life and Times Questionnaire (KLT) consisted of 77 items exploring school related experiences, including bully/victim problems ('traditional forms' and cyberbullying), and a World Health organisation measure of family financial circumstances. The children also 
completed the 27- item KidSCrEEN (ravens -Sieberer et al., 2005; The KidSCrEEN Group Europe, 2006).

Similarly, the 2009 KLT consisted of 88 items exploring school related experiences, including bully/victim problems ('traditional forms' and cyberbullying), internet access and usage, appearance, and the World Health organisation measure of family financial circumstances. As before, the KIDSCREEN (RavensSieberer et al., 2005; The KidSCrEEN Group Europe, 2006) was included in the questionnaire.

The bully/victim questions presented in the 2008 and 2009 KLT are presented in Table 1 below (the last question was not presented in 2009).

Table 1. Bully/Victim Questions Presented in the 2008 and 2009 KLT 
(1) Do you think that pupils at your school get bullied by other pupils? A lot

A little

Not at all

I don't know

(2) Is there someone at your school whose job is to deal with bullying?

Yes

No

I don't know

(3) Does your school have a set of rules on bullying?

Yes

No

I don't know

(4) Have you ever talked about bullying in your class?

Yes

No

I don't know

(5) In the last 2 months, how often did you get physically bullied at

A lot school, for example getting pushed around or threatened or having

A little your belongings stolen?

Not at all

I don't know

(6) In the last 2 months, how often did you get bullied in other ways

A lot

at school such as getting called names, getting left out of games, or

A little

having nasty stories spread about you on purpose?

Not at all

I don't know

(7) Have you ever been bullied by someone sending nasty texts or putting up bad things about you on the Internet?

Yes

No

I don't know

(8) In the last 2 months, did you take part in bullying other children at school

A lot by pushing them around, threatening them or stealing their things?

A little

Not at all

I don't know

(9) In the last 2 months, did you take part in bullying children in other ways A lot at school such as calling them names, leaving them out of games or spreading A little nasty stories about them on purpose?

Not at all

(10) Have you ever taken part in bullying someone by sending nasty texts or putting up bad things about them on the internet?

I don't know Yes No I don't know

The KidSCrEEN (ravens- Sieberer et al., 2005; The KidSCrEEN Group The KidSCrEEN (ravens- Sieberer et al., 2005; The KidSCrEEN Group Europe, 2006) explores respondents' perception of their quality of life across five dimensions: physical well- being (e.g., 'Thinking about the last week, have you felt full of energy?'), psychological well -being (e.g., 'Thinking about the last week, have you felt sad?'), autonomy and parent (e.g., 'Thinking about the last week, have you been able to talk to your parent(s) when you wanted to?'), peers 
and social support (e.g., 'Thinking about the last week, have you and your friends helped each other?'), and school environment (e.g., 'Thinking about the last week, have you been happy at school?').

\section{Procedure}

Ethical permission was obtained from the Ethics Committee in the School of Sociology, Social Policy and Social Work at Queen's University belfast. The department of Education for Northern ireland provided a database of information for all primary schools and their pupils within Northern Ireland. Four of the five Education and Library boards (ELbs) facilitated access to children not attending school but being educated at home.

An information letter was posted to principals of all primary, special, and hospital schools in Northern ireland. This was followed two weeks later with a further letter, instructions for teachers, and a copy of the parental consent form (ELbs sent letters and consent forms to the parents / guardians of children being taught at home). An online questionnaire was available throughout the following month. once the child agreed that s/he wanted to take part, the questionnaire was made available by entering a four digit school identification number. Completion time was approximately 20-2 5 minutes. Each question had a 'skip' option. At the end of the survey, respondents were given the opportunity to suggest questions they felt should be included in any future KLT surveys.

\section{rESULTS}

Bully/Victim Problems descriptive statistics regarding responses to the bully/victim items in the 2008 and 2009 KLT surveys are presented in Table 2 below.

Table 2. Bully/Victim Results

\begin{tabular}{llcccc}
\hline Question & $\begin{array}{l}\text { Response } \\
\text { Options }\end{array}$ & $\begin{array}{c}\mathbf{2 0 0 8} \\
\%\end{array}$ & $\begin{array}{c}\mathbf{2 0 0 8} \\
\mathbf{N}\end{array}$ & $\begin{array}{c}\mathbf{2 0 0 9} \\
\mathbf{\%}\end{array}$ & $\begin{array}{c}\mathbf{2 0 0 9} \\
\mathbf{N}\end{array}$ \\
\hline (1) Do you think that pupils at your school & A lot & $5.4 \%$ & 183 & $5.7 \%$ & 206 \\
get bullied by other pupils? & A little & $45.8 \%$ & 1,566 & $41.7 \%$ & 1,514 \\
& Not at all & $23.8 \%$ & 815 & $25.2 \%$ & 917 \\
& I don't know & $25 \%$ & 854 & $27.4 \%$ & 996
\end{tabular}



(2) Is there someone at your school whose
job is to deal with bullying?

(3) Does your school have a set of rules on bullying?

(4) Have you ever talked about bullying in your class?

(5) In the last 2 months, how often did you get physically bullied at school, for example getting pushed around or threatened or having your belongings stolen?

(6) In the last 2 months, how often did you get bullied in other ways at school such as getting called names, getting left out of games, or having nasty stories spread about you on purpose?

(7) Have you ever been bullied by someone sending nasty texts or putting up bad things about you on the Internet?

(8) In the last 2 months, did you take part in bullying other children at school by pushing them around, threatening them or stealing their things?

(9) In the last 2 months, did you take part in bullying children in other ways at school such as calling them names, leaving them out of games or spreading nasty stories about them on purpose?

(10) Have you ever taken part in bullying someone by sending nasty texts or putting up bad things about them on the internet?

\section{Yes}

No

I don't know

Yes

No

I don't know

Yes

No

I don't know

A lot

A little

Not at all

I don't know

A lot

A little

Not at all

I don't know

Yes

No

I don't know

A lot

A little

Not at all

I don't know

A lot

A little

Not at all

I don't know $\begin{array}{llll}69.6 \% & 2,379 & 70.5 \% & 2,562\end{array}$

$\begin{array}{llll}12.3 \% & 419 & 13 \% & 472\end{array}$

$18.2 \% \quad 621 \quad 16.5 \% \quad 600$

$\begin{array}{llll}86.7 \% & 2,961 \quad 88.7 \% & 3,22\end{array}$

$\begin{array}{llll}3.9 & 133 & 3.8 \% & 137\end{array}$

$9.4 \% \quad 322 \quad 7.6 \% \quad 275$

$\begin{array}{lllll}88 \% & 3,011 & 87,4 \% & 3,184\end{array}$

\begin{tabular}{llll}
$7.2 \%$ & 248 & $7.9 \%$ & 288 \\
\hline
\end{tabular}

$\begin{array}{llll}4.7 \% & 162 & 4.6 \% & 169\end{array}$

$\begin{array}{llll}3.7 \% & 125 & 3.9 \% & 143\end{array}$

$\begin{array}{llll}18.3 \% & 625 & 17.9 \% & 650\end{array}$

$\begin{array}{lllll}73.4 \% & 2,510 & 73.7 \% & 2.678\end{array}$

$\begin{array}{llll}4.7 \% & 161 & 4.5 \% & 165\end{array}$

$8 \% \quad 275 \quad 7.5 \% \quad 272$

$\begin{array}{llll}30.8 \% & 1,053 & 28.7 \% & 1,039\end{array}$

$\begin{array}{llll}55.6 \% & 1.901 & 57.8 \% & 2,095\end{array}$

$5.6 \% \quad 192 \quad 6.1 \% \quad 220$ $\begin{array}{llll}10.3 \% & 353 & 12.9 \% & 470\end{array}$

$\begin{array}{llll}81.2 \% & 2,782 & 80.3 \% & 2,922\end{array}$

$8.5 \% \quad 291 \quad 6.8 \% \quad 248$

$\begin{array}{llll}0.9 \% & 30 & 0.8 \% & 28 \\ 6.9 \% & 235 & 7.7 \% & 279 \\ 87.7 \% & 2,999 & 87.1 \% & 3,166 \\ 4.5 \% & 154 & 4.4 \% & 161\end{array}$

$\begin{array}{llll}0.8 \% & 27 & 0.9 \% & 33\end{array}$

$\begin{array}{llll}12 \% & 410 & 12.2 \% & 443\end{array}$

$\begin{array}{llll}81.9 \% & 2,798 & 82 \% & 2,980\end{array}$

$\begin{array}{llll}5.3 \% & 180 & 4.8 \% & 176\end{array}$

$\begin{array}{llllc}\text { Yes } & 3.4 \% & 115 & \text { Not } & \text { Not } \\ \text { No } & 93,8 \% & 3,204 & \text { presented presented } \\ \text { I don't know } & 2.8 \% & 96 & \text { in } 2009 \text { in } 2009\end{array}$

Across both surveys, it can be seen that whilst approximately half of the children felt that bully/victim problems were an issue at their school, a similar number did not feel that such issues were a problem (Question 1).

A similar pattern can be seen across both surveys in relation to reports of personal experience of being victimized by 'traditional' forms of bullying (i.e., physical or relational / indirect: Questions 5 and 6). Whilst just over one-fi fth of the children experienced physical bullying, over one-t hird had experienced 
relational / indirect forms of peer victimization. As an emerging form of bullying among this age group of children, just over onet enth of children surveyed in both years said that they had experienced cyberbullying (Question 7).

in relation to involvement in bullying others by 'traditional' means, just under one- tenth of the children admitted doing this to peers via physical means (Question 8) and just over one-t enth admitted victimizing their peers by more relational / indirect methods (Question 9). Again, findings were consistent across both surveys. in 2008 , only $3.4 \%$ of children reported that they had cyber-b ullied other children at school (Question 10 [not asked in 2009]).

in relation to the management of bully/victim problems, whilst nearly $90 \%$ of the children in both surveys reported that their school had a set of rules on bullying (Question 3) and that they had talked about bullying in class (Question 4), $70 \%$ (in both surveys) reported that there was someone at school whose job it was to deal with bullying.

\section{KIDSCREEN}

To explore the relationship between involvement in bully/victim problems, either by physical or relational means, correlations were calculated between these items and the subscales of the KidSCrEEN (ravens-S ieberer et al., 2005; The KidSCrEEN Group Europe, 2006) were calculated (see Table 3 below for the statistically significant correlations).

As can be seen from Table 3, there were statistically significant negative relationships between the items assessing victimization (both by physical and relational means) and all of the KidSCrEEN subscales (across both surveys), except for being a victim by physical means and psychical well- being in the 2009 survey. in relation to being a bully, there were similarly negative relationships with some of the sub scales of the KidSCrEEN, although not as pervasive. interestingly, across both surveys, there were no statistically significant relationships between being a bully (using either physical or relational means) and the 'Physical Well-b eing' and 'Peers and Social Support' subscales of the KidSCrEEN.

\section{diSCUSSioN}

The aims of the current research were threefold: (i) to explore the incidence of traditional bullying and cyberbullying among a representative sample of Northern ireland's primary school pupils, (ii) to explore the relationship between involvement in such problems and indices of health and well- being, and (iii) ascertain how the pupils perceived that their school was managing such problems.

Table 3. Correlations between Bully/Victim Items and KIDSCREEN 


\begin{tabular}{|c|c|c|c|c|c|c|c|c|}
\hline Items & Victim1 & Victim2 & Bully1 & $y 2$ & $\mathrm{n} 1$ & Victim2 & Bully1 & Bully2 \\
\hline K1 & $-0.070^{* *}$ & $-0.102^{* *}$ & & & & -0.0 & & \\
\hline 2 & $-0.203^{* *}$ & $-0.288^{* *}$ & & $-0.054^{* *}$ & & $-0.238^{* *}$ & & \\
\hline K3 & $-0.146^{* *}$ & $-0.217^{* *}$ & & $-0.057^{* *}$ & $-0.142^{* 8}$ & $-0.162^{* *}$ & & ** \\
\hline K4 & $-0.127^{* *}$ & $-0.174 * *$ & & & $-0.105^{* 8}$ & $-0.144^{* *}$ & & $-0.058^{* *}$ \\
\hline 5 & $-0.158 * *$ & $-0.190^{* *}$ & $-0.065^{* *}$ & $-0.066^{* *}$ & $-0.124 * *$ & $-0.146^{* *}$ & $-0.051 * *$ & $-0.115^{* *}$ \\
\hline
\end{tabular}

K1 = Kidscreen Physical Wellbeing subscale total; K2 = Kidscreen Psychological Wellbeing subscale total; K3 = Kidscreen Automony and Parent subscale total; K4 = Kidscreen Peers and Social Support subscale total; K5 = Kidscreen School Environment subscale total; Victiml = Last 2 months ever physically bullied at school; Victim 2 = Last 2 months ever bullied other ways; Bully1 = Last 2 months ever bullied other pupil; Bully2 = Last 2 months ever bullied other pupil other ways. ** - Correlation is significant at 0.01 level; * - Correlation is significant at 0.05 level

In relation to the first of these aims, it was found that, across both surveys, approximately half of the children felt that bully/victim problems were an issue at their school. in terms of their own personal experience of involvement in such problems, over $20 \%$ of the children had experienced physical bullying, over onethird had experienced relational / indirect forms of bullying, and over $10 \%$ had experienced cyberbullying. regarding involvement in bullying others, approximately $10 \%$ of the children admitted victimizing their peers either 'physically' or 'relationally', with 3.4\% reporting that they had cyber bullied other children at school (in 2008: question not asked in 2009).

These results regarding the incidence of involvement in 'traditional' bullying are lower than those reported by Collins et al. $(2002$, 2004), where $40.1 \%$ of primary school pupils reported being a victim 'sometimes or more often' and 5\% reported that they were a victim 'frequently', and $24.9 \%$ reporting that they were bullies. The results are, however, higher than those reported by Livesay et al. (2007), where $16.5 \%$ of the primary school pupils reported being bullied 'sometimes or more often' and 5\% reported bullying others 'sometimes or more often.' No comparable data regarding cyberbullying exist in Ni.

The theoretical focus of the questions in this newly developed Kids Life and Times Survey (i.e., based upon olweus), coupled with the robust sampling approach adopted, greatly extends the previous work with this age group of children in Northern ireland and complements the rich picture that is already being obtained by the survey's 'bigger brother', the young Life and Times Survey (Mc Guckin \& Lewis, 2006; Mc Guckin et al., in press a, b).

in relation to the second of these aims, it was found that being a victim (across both surveys) was associated with impaired health and well- being, as assessed by the KidSCrEEN (ravens- Sieberer et al., 2005; The KidSCrEEN Group Europe, 2006). Whilst it was found that being a bully was also associated with some impairment, it was interesting that being a bully was not related to either 'Physical Well-b eing' or 'Peers and Social Support'. Unfortunately, such findings are consistent with both the local (e.g., Cairns \& Lloyd, 2005; Mc Guckin et al., in press a, b) and international literature (e.g., Hawker \& boulton, 
2000) that demonstrates the insidious effects of involvement in bully/victim problems on aspects of health and well- being.

regarding the third of these aims, nearly $90 \%$ of the pupils (across both surveys) reported that their school had a set of rules on bullying and that they had talked about bullying in class. Also, across both surveys, $70 \%$ reported that there was someone at school whose job it was to deal with bullying. This finding becomes interesting for two reasons. Firstly, and in support of previous research in Northern ireland exploring the management of bully/victim problems in the schools (Mc Guckin \& Lewis, 2008), it is clearly evident that the children feel that their schools are doing a lot in terms of being aware of, and managing, bully/ victim problems. Secondly, and more importantly, despite the strong management culture, a significant number of children are still involved in such problem, with the resultant negative effects that this has on health and wellbeing. With the emergence of cyberbullying as an issue among these children, it would be opportune for schools to re- evaluate and update policies and procedures relating to this emerging form for peer aggression. Such help and support is increasing becoming available through the results of EU funded research in the area (e.g., the CyberTraining Project: http://www.cybertraining-p roject.org, CoST Action iS0801: http://sites.google.com/site/costis0801).

Thus, across both surveys, it is apparent that, despite positive reports about how schools manage bully/victim problems, 'traditional' forms of bully/victim problems continue to be pervasive, cyberbullying is an emerging form of bullying among this age -group, and involvement in such problems has a deleterious effect on health and well-b eing. These are not 'Northern irish' problems; rather, they are issues that need to addressed and tackled vigorously across all cultures and societies. The role of school management and the school community, as well as the input from psychologists and other professionals, is becoming even more important, as children continue to develop in a fast changing world. Everyone with an interest in the safety and well- being of children should re -double efforts in terms of prevention and intervention (see Smith et al., 2004), especially in relation to the newly emerging cyberbullying phenomena.

\section{rEFErENCES}

ArK (2008). ArK. Northern ireland Kid Life and Times Survey, 2008 [computer file]. ARK http://www.ark.ac.uk/klt/ [distributor], october 2008.

ArK (2009). ArK. Northern ireland Kid Life and Times Survey, 2009 [computer

file]. ARK http://www.ark.ac.uk/klt/ [distributor], october 2009.

Cairns, E., \& Lloyd, K. (2005). Stress at sixteen. Research Update 33. belfast:

Northern ireland Social and Political Archive (ArK).

Callaghan, S., \& joseph, S. (1995). Selfc oncept and peer victimization among schoolchildren. Personality and Individual Differences, 18, 161- 163.

Campbell, M. A. (2005). Cyber bullying: An old problem in a new guise? Australian Journal of Guidance and Counselling, 15, 68 -76. 
Collins, K., \& bell, r. (1996). Peer perceptions of aggression and bullying behaviour in primary schools in Northern ireland. Annals of the New York Academy of Science, 794, 77 -79.

Collins, K., Mc Aleavy, G., \& Adamson, G. (2002). Bullying in schools: A Northern Ireland study. Research Report Series No.30. bangor, Northern ireland: department of Education for Northern ireland.

Collins, K., Mc Aleavy, G., \& Adamson, G. (2004). bullying in schools: A Northern ireland study. Educational Research, 46, 55- 71.

department of Education for Northern ireland (2003). Welfare and protection of pupils: Education and libraries (Northern Ireland) Order 2003. Circular Number 2003/13. date of issue: june 18, 2003. bangor, Northern ireland: department of Education.

Eron, L. d., Huesmann, r. L., dubow, E., romanoff, r., \& yarnel, P. W. (1987). Childhood aggression and its correlates over 22 years. in d. H. Crowell, i. M. Evans, \& C. r. o'donnell (Eds.) Childhood aggression and violence (pp. 249 -262). New york: Plenum.

Grant, M. (1996). Bullying: A review of the literature and results of a pilot study. Unpublished Masters thesis, University of Ulster at Magee College, Londonderry, Northern ireland.

Goldberg, d., \& Williams, P. (1988). A user's guide to the General Health Questionnaire. Windsor, UK: NFEr- Nelson.

Hawker, d. S. j., \& boulton, M. j. (2000). Twenty years' research on peer victimization and psychosocial maladjustment: A meta- analytic review of crosssectional studies. Journal of Child Psychology \& Psychiatry \& Allied Disciplines, 41, 441- 455.

Livesey, G., Mc Aleavy, G., donegan, T., duffy, j., o'Hagan, C., Adamson, G., \& White, r. (2007). The nature and extent of bullying in schools in the North of Ireland. research report No. 46. bangor, Northern ireland: department of Education for Northern ireland.

Mc Guckin, C., Cummins, P. K., \& Lewis, C. A. (2008). bully/victim problems in Northern ireland's schools: data from the 2000 young Persons' behaviour and Attitude Survey. Individual Differences Research, 6, 280 -288

Mc Guckin, C., Cummins, P. K., \& Lewis, C. A. (2009). bully/victim problems in Northern ireland's schools: data from the 2003 young Persons' behaviour and Attitude Survey. Adolescence, 44, 347358.

Mc Guckin, C., Cummins, P. K., \& Lewis, C. A. (in press). Experiences of school bullying, psychological well -being and stress in Northern ireland: data from the 2005 young Life and Times Survey. Research in Education.

Mc Guckin, C., \& Lewis, C. A. (2006). Experiences of school bullying in Northern ireland: data from the Life and Times Survey. Adolescence, 41, 313320.

Mc Guckin, C., \& Lewis, C. A. (2008). Management of bullying in Northern ireland schools: A pre- legislative survey. Educational Research, 50(1), 923. 
Mc Guckin, C., Lewis, C. A., \& Cummins, P. K. (in press). Experiences of school bullying, psychological well-b eing and stress in Northern ireland: data from the 2004 young Life and Times Survey. Irish Journal of Psychology.

Mc Whirter, L. (2004). Equality and inequalities in health and social care in Northern Ireland: A statistical overview. belfast: department of Health, Social Services and Public Safety.

Nansel, T. r., overpeck, M. d., Haynie, d. L., ruan, W. j., \& Scheidt, P. C. (2003). relationships between bullying and violence among US youth. Archives of Pediatrics and Adolescent Medicine, 157, 348- 353.

Neary, A., \& joseph, S. (1994). Peer victimisation and its relationship to selfconcept and depression among schoolgirls. Personality and Individual Differences, 16, $183-186$.

olweus, d. (1989). Bully/Victim Questionnaire For Students. department of Psychology, University of bergen.

olweus, d. (1991). bully/victim problems among schoolchildren: basic facts and effects of a school-b ased intervention program. in d. j. Pepler \& K. H. rubin (Eds.), The development and treatment of childhood aggression (pp. 411448). Hillsdale, $\mathrm{Nj}$ : Lawrence Erlbaum.

olweus, d. (1996). The Revised Olweus Bully/Victim Questionnaire. bergen, Norway: research Center for Health Promotion (HEMiL), University of bergen, $\mathrm{N}-5015$ bergen, Norway.

Patchin, j. W., \& Hinduja, S. (2006). bullies move beyond the schoolyard: A preliminary look at cyberbullying. Youth Violence and Juvenile Justice, 4, 148-169 ravens Sieberer, U., Gosch, A., rajmil, L., Erhart, M., bruil, j., duer, W., Auquier, P., Power, M., Abel, T., Czemy, L., Mazur, j., Czimbalmos, A., Tountas, y., Hagquist, C., Kilroe, j. and the European KidSCrEEN Group. (2005). KidSCrEEN- 52 quality- of- life measure for children and adolescents. Expert Review of Pharmacoeconomics \& Outcomes Research, 5, 353 -364.

robitail, S., ravens -Sieberer, U., Simeoni, M.C., rajmil, L., bruil, j., Power, M., dür, W., Cloetta, b., Czemy, L., Mazur, j., Czimbalmos, A., Tountas, y., Hagquist, C., Kilroe, Auquier, P., \& the KidSCrEEN Group (2007). Testing the structural and cross- cultural validity of the KidSCrEEN- 27 quality of life questionnaire. Quality of Life Research, 16, 1335- 1345.

Smith, P. K., Morita, y., junger -Tas, j., olweus, d., Catalano, r., \& Slee, P. (Eds.) (1999). The nature of school bullying: A cross-national perspective. London and New york: routledge.

Smith, P. K., Pepler, d. j., \& rigby, K. (Eds.), (2004). Bullying in schools: How successful can interventions be? Cambridge: Cambridge University Press.

Smith, P. K., Mahdavi, j., Carvalho, M., \& Tippett, N. (2006). An investigation into cyberbullying, its forms, awareness and impact, and the relationship between age and gender in cyberbullying. research brief No. rbX03-06. London: dfES.

Taylor, A. (1996). Comparison study of bullying rates in three schools with antibullying programs and three control schools with no anti-b ullying 
programs in Northern Ireland. Unpublished Masters thesis, University of Ulster at jordanstown, belfast, Northern ireland.

The KidSCrEEN Group Europe. (2006). The KidSCrEEN Questionnaires-

Quality of life questionnaires for children and adolescents. Lengerich: Pabst Science Publishers.

yang, K., Chung, H., \& Kim, U. (2003). The effects of school violence on the psychological adjustment of Korean adolescents: A comparative analysis of bullies, victims, and bystanders. in K. yang \& K. Hwang (Eds.), Progress in Asian social psychology: Conceptual and empirical contributions. Contributions in psychology (pp. 263- 275). Westport, CT: Praeger/Greenwood.

ybarra, M. L., \& Mitchell, K. j. (2004). online aggressor/targets, aggressors, and targets: a comparison of associated youth characteristics. Journal of Child Psychology and Psychiatry, 45, 1308 -1316.

ybarra, M. L., \& Mitchell, K. j. (2007). Prevalence and frequency of internet harassment instigation: implications for adolescent health. Journal of Adolescent Health, 41, 189 -195.

ybarra, M. L., Mitchell, K. j., Wolak, j., \& Finkelhor, d. (2006). Examining characteristics and associated distress related to internet harassment: Findings from the second youth internet safety survey. Pediatrics, 118, $1169-1177$.

young Person behaviour and Attitudes Survey (yPbAS) 2003 bulletin. Northern ireland Statistics and research Agency, retrieved March 12, 2008, from http://www.csu.nisra.gov.uk/survey.asp14.htm 
